\title{
What do we have to do with Traumatic Thoracolumbar Fractured and Lateral Dislocated Patients without Neurological Deficit?
}

\author{
Tevfik Yılmaz', Onur Yaman ${ }^{2 *}$, Nail Özdemir ${ }^{2}$, İsmail Ertan Sevin ${ }^{3}$, Ömer Akar ${ }^{4}$ and Sedat Dalbayrak \\ ${ }^{1}$ Department of Neurosurgery, Dicle University, Diyarbakır, Turkey \\ ${ }^{2}$ Tepecik Education and Training Hospital, Clinic of Neurosurgery, Izmir, Turkey \\ ${ }^{3}$ Atatürk Education and Training Hospital, Clinic of Neurosurgery, Izmir, Turkey \\ ${ }^{4}$ Kahramanmaras State Hospital, Neurosurgery, Kahramanmaraş, Turkey \\ ${ }^{5}$ Neurospinal Academy, Istanbul, Turkey
}

\begin{abstract}
Thoracolumbar fracture-dislocations usually cause complete neurological dysfunction under the level of trauma. However, a few patients may not have neurological deficits. It's thought to be responsible for the mechanism of spinal trauma. Aim of surgical treatment is to restore biomechanical stability. In this study we present three traumatic thoracolumbar fracture and lateral dislocation cases without neurological deficit. Both cases had a grade $E$ according to Frankel scale and got 6 points according to Thoracolumbar Injury Classification Severity Scale (TLICS). Patients were treated with long-segment posterior instrumentation via posterior approach. Fracture-dislocation were reducted and stabilized succesfully with posteriror long-segment stabilization via posterior approach. We followed the first patient for 8 months and second patient for 4 years and the third patient for 3 months. Secondary kyphosis deformity didn't develope in any patients during the follow up. Posterior long-segment stabilization is a safe and efficient treatment for thoracolumbar fracture-dislocation. There has been concern whether the stand-alone posterior surgery can prevent secondary kyphosis deformity in mid-term or long-term follow up or not.
\end{abstract}

Keywords: Thoracolumbar; Dislocation; Neurological deficit

\section{Introduction}

Thoracolumbar fracture-dislocations usually cause complete neurological dysfunction under the level of trauma. Accidental fall and motor vehicle accident are the most frequent causes of thoracolumbar fracture-dislocations [1]. However, a few patients may not have neurological deficits [2-13]. This is thought to be dependent on the mechanism of spinal trauma. Aim of surgical treatment is to restore biomechanical stability. In this study we present three traumatic thoracolumbar fracture and lateral dislocation cases without neurological deficit. We will argue the mechanism of trauma, clinical and radiological features and details of the surgery.

\section{Case Report}

\section{Case 1}

A 41-year-old female was referred to our hospital after a car accident. She was unrestrained in the car that had overturned. On

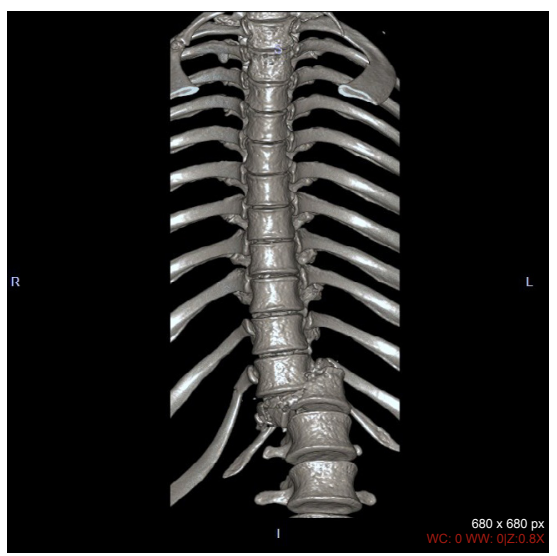

Figure 1: Anteroposterior view of 3-D CT image of thoracolumbar spine shows fracture and lateral dislocation of thoracal 11 to thoracal 12 vertebrae (Case 1 ). physical examination she was oriented and cooperative. Glasgow coma scale was 15. She had a grade E according to Frankel scale and she showed no neurological deficit. Cranial computed tomography (CT) showed no abnormality. CT of thoracolumbar spine scans revealed the fracture and lateral dislocation of Thoracic (Th) 11 to Th 12 vertebrae (Figures 1 and 2). Magnetic resonance imaging (MRI) confirmed the pathology (Figures 3 and 4). According to thoracolumbar injury classification severity score (TLICS) described by Vaccaro, she had 6 points [14], and she had a grade C according to AO classification [15] (Table 1). Operative treatment was pursued.

Patient was intubated in supine position. With the help of neuroinvasive monitoring, patients thoracolumbar corset wasnt removed until the patients position changed from supine to a safety prone position to avoid neurological deterioration. Patient was operated under general anesthesia. Fascia was opened in the midline and paravertebral muscles were dissected laterally. Bilateral pedicles of Th11 were fractured. Left facet of Th11 was separated and rotated to left and corpus of Th12 vertebrae were slided anteriorly. Thoracal 11 and 12 total laminectomy were performed. No dural damage was found. Ligamentum flavum and other ligamentous structures were damaged. Reduction of Th 11-12 lateral dislocation was performed due to spinal cord monitoring. Thoracic (Th) 10 and Lumbar (L) 1 monoaxial transpedicular screw and Th8-9-L2-3 polyaxial transpedicular

*Corresponding author: Onur Yaman, Tepecik Education and Training Hospital, Clinic of Neurosurgery, Izmir, Turkey, Tel: 902324696969; Fax: 0902324330756; E-mail: dronuryaman@yahoo.com

Received February 19, 2014; Accepted March 17, 2014; Published March 20 2014

Citation: Yılmaz T, Yaman O, Özdemir N, Sevin IE, Akar Ö, et al. (2014) What do we have to do with Traumatic Thoracolumbar Fractured and Lateral Dislocated Patients without Neurological Deficit? J Spine 3: 161. doi:10.4172/21657939.1000161

Copyright: $\odot 2014$ Yılmaz T, et al. This is an open-access article distributed under the terms of the Creative Commons Attribution License, which permits unrestricted use, distribution, and reproduction in any medium, provided the original author and source are credited. 
Citation: Yılmaz T, Yaman O, Özdemir N, Sevin IE, Akar Ö, et al. (2014) What do we have to do with Traumatic Thoracolumbar Fractured and Lateral Dislocated Patients without Neurological Deficit? J Spine 3: 161. doi:10.4172/2165-7939.1000161

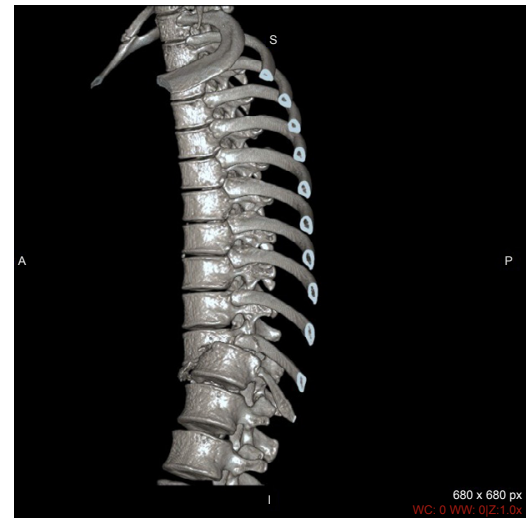

Figure 2: Lateral view of 3-D CT image of thoracolumbar spine shows fracture and lateral dislocation of thoracal 11 to thoracal 12 vertebrae (Case 1 ).

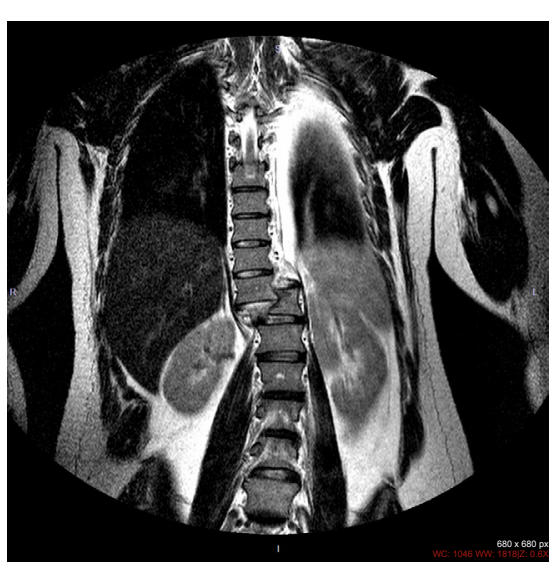

Figure 3: Thoracolumbar coronal MRI section shows Th11-Th12 fracturelateral dislocation (Case 1).

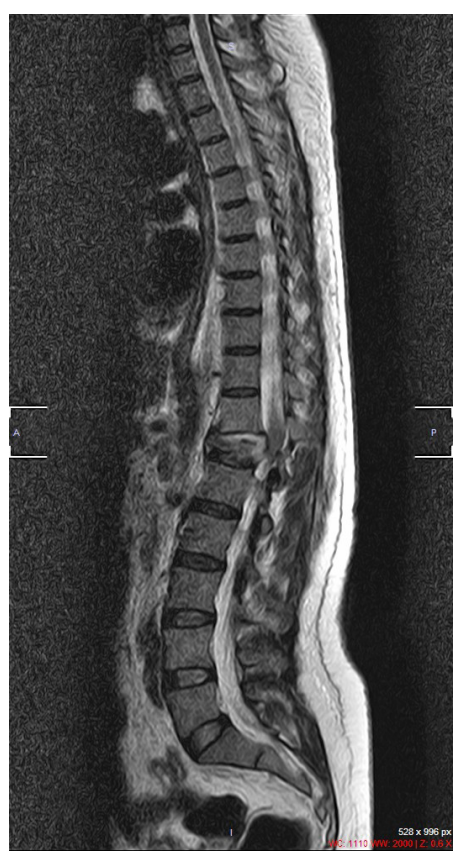

Figure 4: Thoracolumbar sagittal MRI section shows Th11-Th12 fracturelateral dislocation (Case 1). screw was applied under fluoroscopic guidance. Construction was strengthened with rods and connected with a cross-link. Postoperative lumbar CT showed the realignment of spinal column (Figures 5 and 6). Patient was neurologically intact after surgery. At the 5 months followup examination she has no complaints and no kyphosis deformity developed.

\section{Case 2}

A 24-year-old female fell down from 2 meter height. In the neurological examination she had no neurological deficit. She had a grade E according to Frankel scale. Cranial CT showed left temporal acute subdural hematoma, left frontal contusion, brain edema and subarachnoid hemorrhage. Examination of lumbosacral vertebrae and lumbar CT showed L 1-2 fracture and lateral dislocation (Figures 7 and 8). Magnetic resonance imaging (MRI) confirmed the pathology (Figure 9). Antiedema treatment was applied for brain edema. According to

\begin{tabular}{|c|c|c|c|c|c|}
\hline $\begin{array}{c}\text { Age/ } \\
\text { gender }\end{array}$ & $\begin{array}{c}\text { Cause of } \\
\text { injury }\end{array}$ & $\begin{array}{c}\text { Frankel } \\
\text { classification }\end{array}$ & $\begin{array}{c}\text { TLICS } \\
\text { classification }\end{array}$ & $\begin{array}{c}\text { AO } \\
\text { Classification }\end{array}$ & $\begin{array}{c}\text { Level of } \\
\text { dislocation }\end{array}$ \\
\hline $41 / F$ & $\begin{array}{c}\text { Motor vehicle } \\
\text { accident }\end{array}$ & E & 6 points & Type C & $\begin{array}{c}\text { Thoracal } \\
11-12\end{array}$ \\
\hline $24 / F$ & Fall & E & 6 points & Type C & Lumbar 1-2 \\
\hline $35 / M$ & Fall & E & 6 points & Type C & $\begin{array}{c}\text { Thoracal } \\
11-12\end{array}$ \\
\hline
\end{tabular}

Table 1: Preoperative features of the patients.

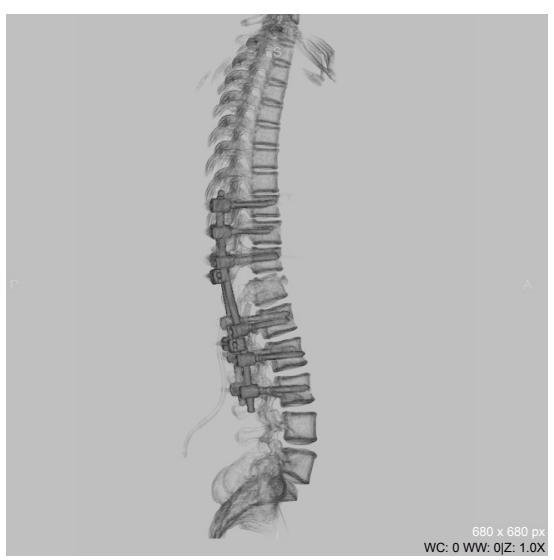

Figures 5: Postoperative 3-D CT images show the realignment of spinal column (Case 1).

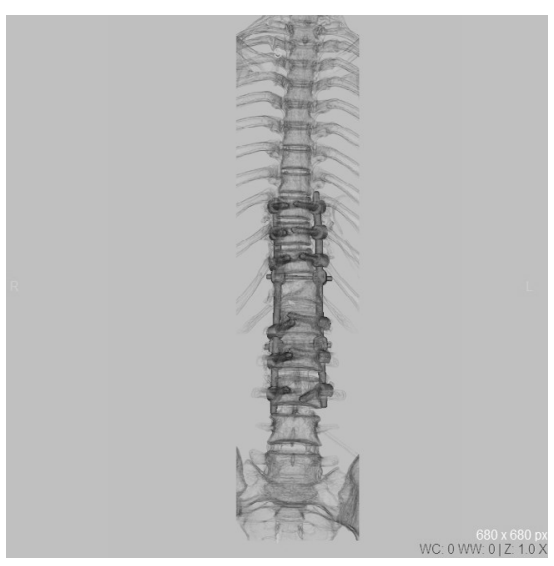

Figures 6: Postoperative 3-D CT images show the realignment of spinal column (Case 1). 
Citation: Yılmaz T, Yaman O, Özdemir N, Sevin IE, Akar Ö, et al. (2014) What do we have to do with Traumatic Thoracolumbar Fractured and Lateral Dislocated Patients without Neurological Deficit? J Spine 3: 161. doi:10.4172/2165-7939.1000161

Page 3 of 5

thoracolumbar injury classification severity score (TLICS) she had 6 points. And she had a grade $\mathrm{C}$ according to AO classification. Operative treatment was pursued.

Patient was positioned in the prone position under general anesthesia. Fascia was opened in the midline and paravertebral muscles were dissected laterally. Facet between L1 and L2 was separated and rotated to right. Vertebral corpus of L1 was slided anteriorly. Right pedicle of L1 and bilateral pedicle of L2 were fractured. L1 and L2 total laminectomy were performed. Th10-L4 posterior segmental enstrumantation and reduction of L1-2 lateral dislocation was performed. Th12-L1-2 monoaxial transpedicular screw and Th1011-L3-4 polyaxial instrumentation transpedicular screws were placed under fluoroscopic and spinal cord monitoring guidance. Construction was strengthened with rods and connected with crosslinks. Localization of the screws were controlled with postoperative radiography and lumbar CT (Figure 10). Patient was neurologically
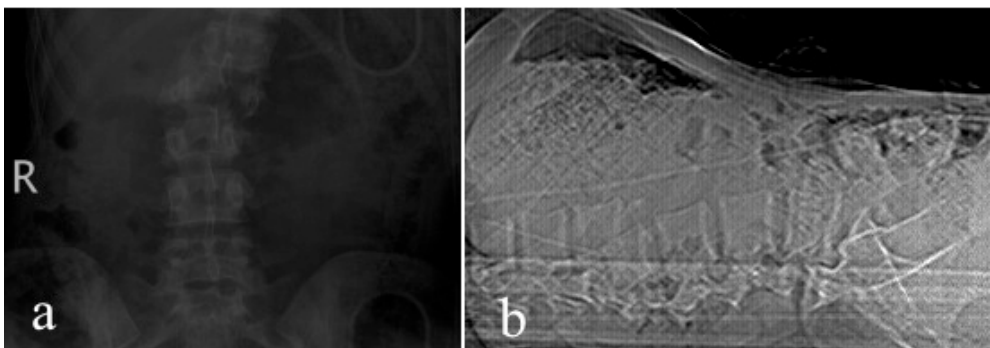

Figure 7a and b: Anteroposterior and lateral view of lumbosacral vertebrae radiogram show L1-2 fracture and lateral dislocation (Case 2).
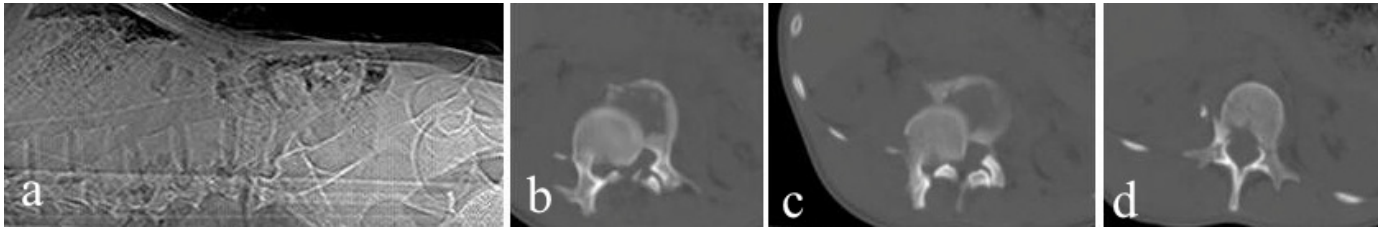

Figure 8a-d: Axial sections of lumbar $C T$ show the $L$ 1-2 fracture and lateral dislocation.

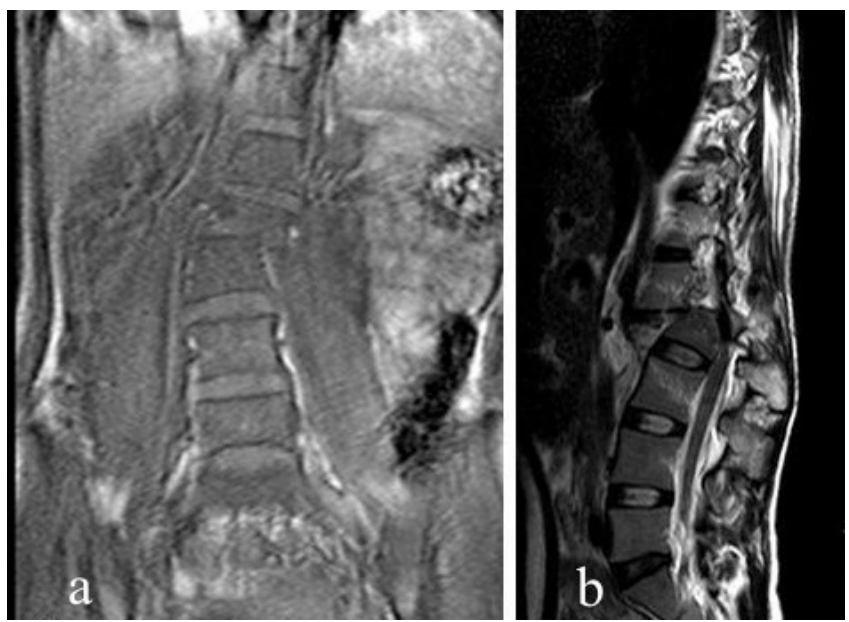

Figure 9a and b: Thoracolumbar coronal and sagittal MRI sections show L1-2 fracture-lateral dislocation (Case 2).
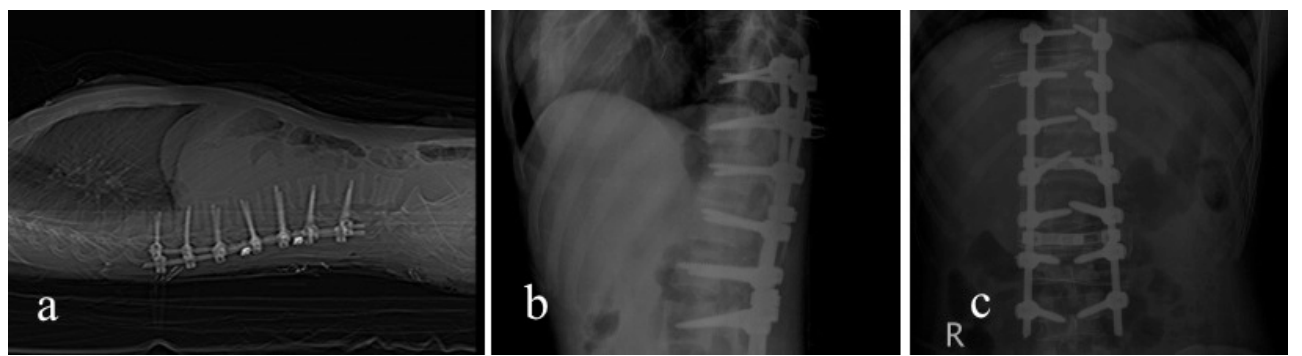

Figure 10a-c: Postoperative CT images show the realignment of spinal column (Case 2). 
intact after surgery. In the third day after surgery level of consciousness was decreased. Cranial CT showed the increase of brain edema and subdural hematoma. Right frontotemporoparital craniectomy and duraplasty were performed. One week after the surgery, she had an improved level of consciousness. At the 4 years follow-up examination, she had no complaints and no kyphosis deformity developed.

\section{Case 3}

A 35-year-old male failed down from 6 meter height. In the neurological examination he had no neurological deficit. He had a grade E according to Frankel scale. Examination of thoracolumbar vertebrae CT showed Th 11-12 fracture and lateral dislocation (Figure 11). According to thoracolumbar injury classification severity score (TLICS) he had 6 points. And he had a grade $\mathrm{C}$ according to AO classification. Operative treatment was pursued.

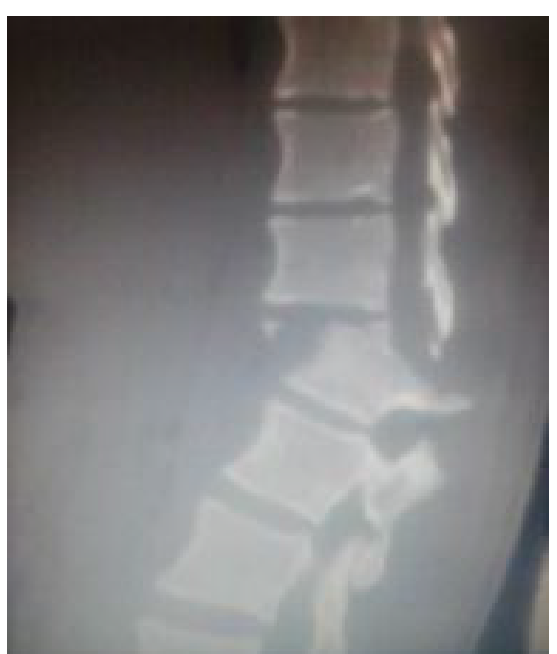

Figure 11: Lateral view of thoracolumbar spine shows fracture and dislocation of thoracal 11 to thoracal 12 vertebrae (Case 3 ).



Figure 12: Postoperative lateral view of thoracolumbar spine shows the realignment of spinal column (Case 3 ).
Patient was positioned in the prone position under general anesthesia. Fascia was opened in the midline and paravertebral muscles were dissected laterally. Bilateral pedicle of Th11 were fractured. Facet between Th11 and Th12 was separated and rotated. Vertebral corpus of Th11 was slided anteriorly. Th11 and Th12 total laminectomy were performed. Th10-L1 posterior segmental enstrumantation and reduction of Th11-12 dislocation was performed. Construction was strengthen with rods and connected with cross-links (Figure 12). Patient was neurologically intact after surgery. Spinal cord monitoring was used during the surgery. At the 3 months follow-up examination, he had no complaint and no kyphosis deformity developed.

\section{Discussion}

Thoracolumbar junction injury represents a mechanical transition zone between the rigid kyphotic thoracic and mobile lordotic lumbar spine. In the United States $72.5 \%$ of the spine injuries are found in thoracic and lumbar spine [16]. Thoracolumbar fracture-dislocations without neurologic deficits are rare. Two main factors that determine the status are the mechanism of the trauma and the structure of patients bone and ligament [3].

Due to the bilateral pedicle fracture after trauma, the posterior elements may be harmed in the affected region and may slide posteriorly and laterally $[2,3,12]$. Also the dislocation of anterior elements may cause spontaneous decompression and the diameter of spinal channel enlarges [3]. The fracture of bilateral pedicle of Th11 in our first case and fracture of bilateral pedicle of $\mathrm{L} 2$ in our second case and the fracture of bilateral pedicle of Th11 caused spontaneous decompression of the spinal channel. In addition, other important prognostic factor is the ligamentous elasticity $[9,12]$.

Several surgical approaches are available for the thoracolumbar fracture-lateral dislocation such as: anterolateral approach, posterior approach and combined approach. The choice of surgical approach depends on surgeons decision. There has been a controversy whether only posterior surgery can stabilize thoracolumbar injury. Biomechanical study found no difference between anterior versus posterior fixation as long as the long-segment posterior instrumentation was used [1]. Some authors reported satisfactory results for thoracolumbar junction injury via anterior approach only [15,17]. According to our knowledge and experience, long-segment posterior instrumentation via posterior approach should be the first choice for the reduction and stabilization of fracture-lateral dislocation of thoracolumbar junction $[3,10]$. Because posterior approach allows the easy reduction of dislocation and total laminectomy should be performed for the dislocated level to enlarge the channel to protect spinal cord during the derotation maneuver. Two-or three-vertebrae fixation techniques is still controversial for stabilization excluding the fractured vertebrae. There is one published reports on stress distribution on the screws with two- or three- vertebrae fixation techniques for the treatment of spondylolisthesis in the literature [18]. Sixteen fresh specimens of human lumbar spines were used in Wus study [19]. The model was generated by 2- (group A) or 3- vertebrae (group B). The samples were tested under flexion/extenhe sion, left/ right lateral bending, and axial compression loading. In most loading conditions, stress in reduction screws in 2-vertebrae fixation technique was higher in 3- vertebrae fixation technique. The 3-vertebrae fixation technique might effectively reduce stress on the reduction screws and decrease the probability of fatique fractures of the screws. The screws in one level above and one level below the dislocated region should be monoaxial screws to strengthen the construction. After putting the screws, the rod should be constructed according to dislocated side to place the rod easily. While one surgeon applies distraction on the rod 
Citation: Yılmaz T, Yaman O, Özdemir N, Sevin IE, Akar Ö, et al. (2014) What do we have to do with Traumatic Thoracolumbar Fractured and Lateral Dislocated Patients without Neurological Deficit? J Spine 3: 161. doi:10.4172/2165-7939.1000161

Page 5 of 5

on the dislocated segment, the other surgeon reduces the system with derotation maneuver. After the reduction of the dislocated segment, the other rod should be placed and heads of the screws must be fixed. Then the rod that was used for derotation maneuver has to be constructed according to thoracal kyphosis and lumbal lordosis with the helping of in-situ benders and then the rod has to be fixed. There are two main reasons for choosing long instrumentation. One of them is to strengthen the system to protect pedicles from harming during derotation maneuver. Other one is to decrease the risk of hardware failure in the long term follow-up [16]. Cho et al. [20] compared the results of short fusion versus long fusion for degenerative lumbar scoliosis. The short fusion group included 28 patients, and the long fusion group included 22 patients. Late complications reported that adjacent segment disease, loosening of screws, and pseudoarthrosis. Adjacent segment disease developed in ten patients (36\%) in short fusion group, and in five patients (23\%) in the long fusion group. So that we decided to perform long instrumentation and long fusion in our cases $[3,11,21]$. In the first case, Th9-L3 posterior stabilization has been performed after the reduction of Th11-12 level. In the second case, Th10-L4 posterior stabilization has been performed after the reduction of L1-2 level. Th10-L1 posterior stabilization has been performed and posterolateral fusion has been done in all cases.

\section{Conclusion}

In our opinion, posterior approach is a safe and efficient treatment for thoracolumbar fracture-dislocation. There has been concern whether the stand-alone posterior surgery can prevent secondary kyphosis deformity in mid-term or long-term follow up or not. We followed the first patient for 8 months and second patient for 4 years and the third patient for 3 months. Secondary kyphosis deformity didnt develop in the second patient during the follow up for 4 years. If secondary kyphosis deformity occurs in the mid-term or long-term follow up for the first and second patients, we will add an anterior operation to strengthen the construction.

\section{References}

1. Eichholz KM, Hitchon PW, From A, Rubenbauer P, Nakamura S, et al. (2004) Biomechanical testing of anterior and posterior thoracolumbar instrumentation in the cadaveric spine. Invited submission from from the Joint Section Meeting on Disorders of the Spine and Peripheral Nerves, March 2004. J Neurosurgery Spine 1: 116-121.

2. Abdel-Fattah H, Rizk AH (1990) Complete fracture-dislocation of the lower lumbar spine with spontaneous neurologic decompression. Clin Orthop Relat Res 140-143.

3. Akay KM, Baysefer A, Kayali H, Beduk A, Timurkaynak E (2003) Fracture and lateral dislocation of the T12-L1 vertebrae without neurological deficit--case report. Neurol Med Chir (Tokyo) 43: 267-270.

4. Chen WC (1999) Complete fracture-dislocation of the lumbar spine without paraplegia. Int Orthop 23: 355-357.

5. de Lucas JC, Alvarez L, Abril JC, Calvo E (1994) Fracture-dislocation of the thoracic spine without neurological lesion. Injury 25: 105-107.

6. Denis F, Burkus JK (1991) Lateral distraction injuries to the thoracic and lumbar spine. A report of three cases. J Bone Joint Surg Am 73: 1049-1053.
7. Gertzbein SD (1992) Scoliosis Research Society. Multicenter spine fracture study. Spine (Phila Pa 1976) 17: 528-540.

8. Guzel A, Belen D, Tatli M, Simsek S, Guzel E (2006) Complete L1-L2 latera dislocation without fracture and neurologic deficit in a child. Pediatr Neurosurg 42: 183-186.

9. Korovessis P, Sidiropoulos P, Dimas A (1994) Complete fracture-dislocation of the thoracic spine without neurologic deficit: case report. J Trauma 36: 122-124.

10. Liljenqvist $U$, Halm H, Castro WH, Mommsen $U$ (1995) Thoracic fracturedislocations without spinal cord injury: a case report and literature review. Eur Spine J 4: 252-256.

11. Miyasaka Y, Satomi K, Sugihara S, Tahara Y, Hayashi T, et al. (1993) Posterior fracture-dislocation of the thoracic spine without neurologic deficit. A case report and short literature review. Spine (Phila Pa 1976) 18: 2351-2354.

12. Simpson AH, Williamson DM, Golding SJ, Houghton GR (1990) Thoracic spine translocation without cord injury. J Bone Joint Surg $\mathrm{Br} 72$ : 80-83.

13. Villanueva C, Pellisé F, Bagó J, Cardona X (1994) Lateral distraction injury to the lumbar spine. Report of spontaneous reduction. Spine (Phila Pa 1976) 19: 846-848.

14. Vaccaro AR, Zeiller SC, Hulbert RJ, Anderson PA, Harris M, et al. (2005) The thoracolomber injury severity score: a proposed treatment algorithm. J Spinal Disord Tech 18: 209-215.

15. Aebi M (2010) Classification of thoracolumbar fractures and dislocations. Eur Spine J 19 Suppl 1: S2-7.

16. Hu R, Mustard CA, Burns C (1996) Epidemiology of incident spinal fracture in a complete population. Spine (Phila Pa 1976) 21: 492-499.

17. Sasso RC, Best NM, Reilly TM, McGuire RA Jr (2005) Anterior-only stabilization of three-column thoracolumbar injuries. J Spinal Disord Tech 18: S7-S14.

18. Wood KB, Bohn D, Mehbod A (2005) Anterior versus posterior treatment of stable thoracolumbar burst fractures without neurologic deficit: a prospective, randomized study. J Spinal Disord Tech 18: S15-S23.

19. Wu Zx, Zhan C, Cui G, Liu D, Won SY, et al. (2010) Stres distribution on the screws in posterior lumbar fusion of istmic spondylolisthesis with 2- or 3- vertebra fixation techniques: a biomechanical cadaveric study. Journal of Surgical Research 176: 95-101.

20. Cho KJ, Suk SI, Park SR, Kim JH, Kim SS, et al. (2008) Short fusion versus long fusion for degenerative lumbar scoliosis. Eur Spine J 17: 650-656.

21. Inamasu J, Guiot BH, Nakatsukasa M (2008) Posterior instrumentation surgery for thoracolumbar junction injury causing neurologic deficit. Neurol Med Chir (Tokyo) 48: 15-21. 